\title{
AMERICAN SOCIETY OF PEDIATRIC NEPHROLOGY
} PROGRAM FOR THE ANNUAL MEETING

April 27, 1987; 8:45 A.M.

Disneyland Hotel, Anaheim, California

MARINA BALLROOM 4

(Hote1 Convention Center)

\author{
8:15 A.M. Welcome and Introduction to the Program \\ Russel1 W. Chesney, M.D., 1987 ASPN President \\ MORNING SESSION: HEMOLYTIC UREMIC SYNDROME \\ Symposium Coordinator: Bernard S. Kaplan, M.B., B.Ch. \\ 8:30 A.M. "Pathogenesis of Hemolytic-Uremic Syndrome" \\ Bernard S. Kaplan, M.B., B.Ch., Montreal Children's \\ Hospital, Montreal \\ 9:00 A.M. "Vero Toxin E. Coli Associated Hemolytic-Uremic Syndrome" \\ Mohamed Karmali, Ph.D., Hospital for Sick Children, Toronto \\ $9: 30$ A.M. COFFEE BREAK \\ 10:00 A.M. "Platelet Function in Hemolytic-Uremic Syndrome" \\ Michael Levine, M.D., Hospitals for Sick Children, London \\ 10:30 A.M. "Recurrence of Hemolytic-Uremic Syndrome Post-transplant" \\ 11:00 A.M. Discussion \\ Diane Hebert, M.D., Hospital for sick Children, Toronto
}

AFTERNOON SESSION: NEW DEVELOPMENTS IN TRANSPLANTATION IMMUNOLOGY

Symposium Coordinator: Robert B. Ettenger, M.D.

12:30 P.M. "Allograft Rejection: Mechanisms, Diagnosis and Treatment" J. Harold Helderman, M.D., University of Texas, Southwestern Medical School, Dallas

1:00 P.M. "The Role of Histocompatibility Antigen Matching and Test to Detect Presensitization in the Cyclosporine Era" Nancy Goeken, Ph.D., University of Iowa, Iowa City

1:30 P.M. "Theoretical and Practical Consideration in the Use of Monoclonal OKT3 as Treatment for Rejection in Children Douglas Norman, M.D., University of Oregon, Portland

2:30 P.M. "Blood Transfusions in Living-Related and Cadaveric

Transplantation: Pluses and Minuses" Robert B. Ettenger, M.D., UCLA, Los Angeles

3:00 P.M. Discussion

ADJOURN SCIENTIFIC PROGRAM

3:30 P.M. ASPN ANNUAL BUSINESS MEETING (Members Only)

4:30 P.M. Cocktail Party (Members and Invited Guests)

MEMBERS AND GUESTS ARE REMINDED TO ATTEND THE APS-SPR POSTER SESSION AT THE CONCLUSION OF THE PROGRAM 